\title{
PT community meet in Istanbul: proficiency testing workshop
}

\author{
Brian Brookman • Ender Okandan
}

Published online: 20 July 2012

(C) Springer-Verlag 2012

The historic city of Istanbul, known for where the East meets the West, became the meeting place for the global proficiency testing (PT) and external quality assurance (EQA) community for 4 days in October 2011. This was the 7th international PT workshop on Proficiency Testing in Analytical Chemistry, Microbiology and Laboratory Medicine organized by the EURACHEM Proficiency Testing Working Group in association with EQALM and CITAC. The workshop was supported locally by several Turkish organizations including the Middle East Technical University (METU), the Petroleum Research Center, EURACHEM-Türkiye, TÜBÍTAK UME and TÜRKAK.

The wonderful setting on the coast of the Sea of Marmara provided the perfect location for this successful workshop which once again provided an excellent opportunity for providers, users and regulators of PT/EQA to come together to discuss a wide range of key issues across the three disciplines of analytical chemistry, microbiology and laboratory medicine. The 233 delegates attending from 54 different counties ensured a truly global perspective.

Since the last (6th) PT workshop held in Rome during October 2008, there have been a number of developments in the field of proficiency testing, one of the most notable being the publication of ISO/IEC 17043, the new international standard for the competence of PT/EQA providers, addressing the requirements for the development and operation of PT/EQA schemes. This new standard has been

B. Brookman $(\square)$

LGC Standards Proficiency Testing, Bury, UK

e-mail: Brian.Brookman@lgcpt.com

E. Okandan

METU Petroleum Research Center, Ankara, Turkey

e-mail: okandan@metu.edu.tr adopted by the International Laboratory Accreditation Cooperation (ILAC) as the requirements against which PT/ EQA providers should be accredited. With the publication and its subsequent adoption by ILAC, this has led to an increase in the number of $\mathrm{PT} / \mathrm{EQA}$ providers being accredited around the world. This workshop, therefore, specifically addressed the experiences of implementing ISO/IEC 17043 both from the views of the PT/EQA providers and the accreditation bodies.

In addition to addressing the implementation of ISO/IEC 17043, this workshop focused on further developments in performance assessment in microbiology and qualitative schemes, the status and needs of PT/EQA in developing areas of the world and advancements in pre- and postanalytical PT/EQA.

These important topics addressed at this workshop were explored and discussed through a series of lectures and working group discussions. The diverse range of international delegates attending from different sectors provided a beneficial environment for the cross-fertilization of ideas. The workshop was enriched further with 52 poster contributions covering a wide range of topics and experiences concerned with PT/EQA. In conjunction with the workshop, training sessions on "Establishing Traceability and Uncertainty of Assigned Values" and "Assisting Participants to Assess/Estimate Their Measurement Uncertainty Using PT Results" were provided.

This latest workshop once again proved a great success thanks to the hard work of the local organizers, the quality of the presentations and posters and just as importantly the active participation of all the delegates leading to lively debate and fruitful discussions. We are pleased to provide the papers on many of the presentations, posters and working group discussions in this Topical Focus on PT/ EQA issue of the Journal. 
Building on the success of this workshop, initial plans are now underway for the 8th workshop which will be held in Berlin, Germany, during 6-9 October 2014.

\section{Brian Brookman}

Chair of Workshop Scientific Committee

\section{Ender Okandan}

Chair of Workshop Local Organising Committee

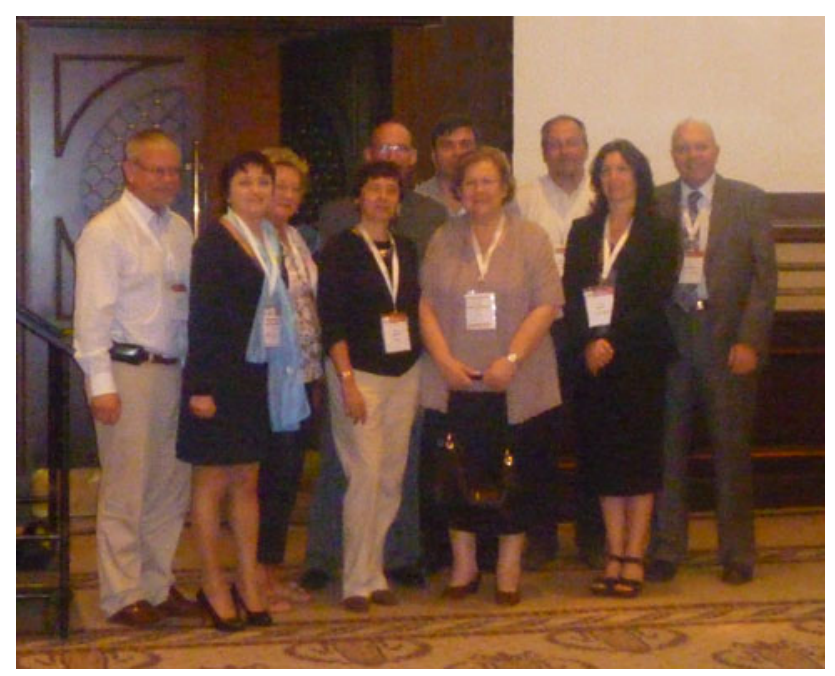

The EURACHEM PT WG at the Workshop in Istanbul (left to right)
Piotr Robouch, Institute for Reference Materials and Measurements, EU

Marina Patriarca, Istituto Superiore di Sanità, Italy

Minna Loikkanen, Lab Quality, Finland

Ewa Bulska, University of Warsaw, Poland

Kees van Putten, DUCARES B.V., The Netherlands

Owen Butler, Health \& Safety Laboratory, UK

Ender Okandan, METU Petroleum Research Center, Turkey

Michael Koch, University of Stuttgart, Germany

Tracey Noblett, LGC Standards Proficiency Testing, UK

Brian Brookman, LGC Standards Proficiency Testing, UK 